\title{
PENGARUH MODEL PEMBELAJARAN INKUIRI TERHADAP HASIL BELAJAR SISWA PADA MATERI POKOK SUHU DAN KALOR DI KELAS X SEMESTER II SMA NEGERI 4 MEDAN T.P 2014/2015
}

\author{
Rika Vera M Situmorang dan Rappel Situmorang \\ Jurusan Fisika FMIPA Universitas Negeri Medan \\ Jalan Willem Iskandar Pasar V Medan, Sumatera Utara \\ rikaverasitumorang@yahoo.co.id
}

\begin{abstract}
ABSTRAK
Penelitian ini bertujuan untuk mengetahui pengaruh model pembelajaran inkuiri terhadap hasil belajar siswa pada materi pokok Suhu dan Kalor. Jenis penelitian ini adalah quasi eksperimen dengan populasi seluruh siswa kelas $\mathrm{X}$ yang terdiri dari 11 kelas MIA. Pengambilan sampel dilakukan dengan cara cluster random sampling yaitu, kelas X-7 dengan jumlah siswa 38 orang, menggunakan model pembelajaran inkuiri dan kelas X-3 dengan jumlah siswa 35 orang, mengggunakan model pembelajaran konvensional. Instrumen yang digunakan yaitu: untuk tes hasil belajar berupa tes pilihan berganda yang berjumlah 20 soal yang sebelumnya telah diuji validitasnya oleh ahli, dan untuk observasi aktivitas belajar siswa, sudah disusun secara sistematis pada lembar observasi. Hasil penelitian menunjukkan bahwa rata-rata persentase aktivitas belajar siswa dengan menggunakan model pembelajaran inkuiri tergolong sangat baik untuk setiap aspek penilaian, dan untuk siswa dengan menggunakan model pembelajaran konvensional untuk aspek visual, listening, motor, dan mental tergolong tidak baik, dan untuk aspek oral dan emotional tergolong cukup baik, serta aspek writing tergolong baik. Berdasarkan analisis data diperoleh bahwa bahwa ada pengaruh yang signifikan model pembelajaran inkuiri terhadap hasil belajar siswa pada materi pokok Suhu dan Kalor.
\end{abstract}

Kata Kunci: model pembelajaran inkuiri, konvensional, hasil belajar, aktivitas.

\section{ABSTRACT}

This research aimed to know about The Effect of Inquiry Learning Model on the Learning Result of Students in the Subject Matter of Temperature and Heat. This Research was quasi experiment type by all the Tenth Students of elevent MIA classes. The Sample was taken by using Cluster Random Sampling, They were the Tenth - Seven grade which had 38 students using Inquiry Learning Model, while the Tenth - Three grade which had 35 students using Convensional Learning Model. The Instrument was used as Multiple Choice of 20 questions for the learning result test which its validation had been studied by the experts, and to observe the student learning activities had arranged in to the sheet of observation systematically. The research result showed that the percentage of calculation average of student learning activities using Inquiry Learning Model as very good for each aspect of assessment, while the Convensional Learning Model usage was not good for each aspect such as, visual, listening, motor, and mentality, otherwise it was good enough for Oral and Emotion aspect, and even the Writing aspect was good also. Base on the data analysis gained that there was the 
Effect of Inquiry Learning Model on the Learning Result of Students in the Subject of Temperature and Heat.

Keywords: Inquiry Learning Model, Conventional, Learning Result, dan Activities 


\section{INTRODUCTION}

Di abad ke-21, sistem pendidikan nasional menghadapi tantangan yang sangat kompleks dalam menyiapkan kualitas sumber daya manusia (SDM) yang mampu bersaing di era global. Upaya yang tepat untuk menyiapkan sumber daya manusia (SDM) yang berkualitas dan satusatunya wadah yang dapat dipandang dan seyogyanya berfungsi sabagai alat untuk membangun SDM yang bermutu tinggi adalah pendidikan (Trianto, 2011).

Lie (2010) mengatakan bahwa "pada abad 21 ini perlu menelaah kembali praktik-praktik pembelajaran di sekolahsekolah. Ada persepsi umum yang sudah berakar dalam dunia pendidikan yaitu sudah merupakam tugas guru untuk mengajar dan menyodori siswa dengan muatan-muatan informasi dan pengetahuan, guru dipandang oleh siswa sebagai mahatahu dan sumber informasi. Lebih celaka lagi, siswa belajar dalam situasi yang membebani dan menakutkan karena dibayangi oleh tuntutan-tututan mengejar nilai-nilai tes dan ujian yang tinggi”.

Hosnan (2014) tertulis :"I have never seen a good school without a good teacher", persoalan guru dan profesinya merupakan hal yang sangat memprihatinkan bagi upaya pencapaian efektivitas sekolah. Dalam keseluruhan proses pendidikan di sekolah maka pembelajaran merupakan aktivitas yang paling utama. Keberhasilan pencapaian tujuan pendidikan banyak bergantung pada bagaiman

proses pembelajaran dapat berlangsung secara efektif.

Salah satu ilmu pengetahuan yang diajarkan oleh guru di sekolah adalah pelajaran Fisika. Fisika mempelajari gejala alam yang tak hidup atau materi dalam lingkup ruang dan waktu". Dalam Giancoli (2001) disimpulkan bahwa " sains adalah suatu aktivitas kreatif yang dalam banyak hal menyerupai aktivitas kreatif pikiran manusia". Faktanya banyak siswa beranggapan pelajaran Fisika sulit. Seperti : banyak rumus, dan tidak ada manfaat yang signifikan jika dipelajari karena Fisika diajarkan hanya teori dan rumus matematis, sehingga siswa merasa bosan, hal ini juga yang dialami oleh penulis selama melaksanakan PPLT (Praktek Pengalaman Lapangan Terpadu), seharusnya fisika dihubungkan dengan kehidupan sehari-hari dan dibuktikan dengan eksperimen di laboratorium.

Berdasarkan hasil studi pendahuluan penulis kepada siswa kelas XI di SMA Negeri 4 Medan, dengan memberikan instrumen berupa angket kepada siswa dan seorang guru Fisika. Dari 46 orang siswa yang diberikan angket, hanya 3 orang yang menyukai pelajaran Fisika, dan hanya 1 orang yang menganggap Fisika itu mudah dan menyenangkan. Kemudian 38 orang yang mengikuti pelajaran Fisika di luar sekolah seperti bimbingan belajar maupun privat, namun nilai ulangan harian Fisika mereka masih rendah sedangkan Kriteria Ketuntasan Minimal (KKM) untuk pelajaran Fisika adalah 70. Dari angket juga diperoleh bahwa proses pembelajaran Fisika di kelas masih berpusat pada guru. Guru juga sudah menghubungkan materi pelajaran dengan kehidupan sehari-hari, namun tidak disertai dengan pembuktian melalui eksperimen dengan alasan jumlah siswa yang terlalu banyak.

Hal ini memungkinkan membuat siswa beranggapan pelajaran Fisika itu rumit dan tidak menarik. Untuk itu diperlukan suatu model pembelajaran yang tepat yang dapat mempermudah siswa untuk memahami materi Fisika serta mengajak siswa melakukan eksperimen/praktikum sehingga tanggapan siswa terhadap pelajaran Fisika nantinya akan berubah menjadi lebih baik. Salah satu cara yang dapat digunakan adalah dengan menggunakan model pembelajaran yang berpusat pada siswa dan melakukan praktikum. Dengan aktifnya siswa dalam pembelajaran maka akan lebih baik karena siswa secara langsung diajak untuk mencari pengetahuan tersebut. Menurut penulis model pembelajaran inkuiri dapat 
digunakan berdasarkan masalah yang telah diuraikan di atas

Pembelajaran inkuiri menekankan kepada proses mencari dan menemukan. Dalam upaya peningkatan mutu belajar, guru perlu memberikan kesempatan kepada siswa untuk melakukan pengamatan, bertanya, mengajukan dugaan-dugaan, mengumpulkan data, dan menyimpulkan sendiri melalui siklus proses menemukan seperti itu, diharapkan pengetahuan dan pengalaman siswa dipahami sebagai pengetahuan dan pengalaman yang dari, oleh, dan untuk mereka. Ketika siswa menemukan sesuatu yang dicari sendiri, daya ingatnya akan lebih melekat dibandingkan orang lain yang menemukannya (Hosnan, 2014).

Tarigan (2012) melakukan penelitian menggunakan model pembelajaran inkuiri menyatakan bahwa ada perbedaan signifikan hasil belajar siswa yang diajar dengan model pembelajaran inkuiri dan konvensional, hal yang sama juga didapatkan oleh Sari (2013) yang melakukan penelitian di SMA Negeri 16 Medan. Penggunaan model yang sama, oleh Tiarmaida (2014), hasil penelitian menunjukkan bahwa hasil belajar kelas eksperimen lebih tinggi daripada kelas kontrol.

Berdasarkan latar belakang masalah di atas, maka penulis tertarik untuk melakukan penelitian dengan tujuan untuk mengetahui pengaruh model pembelajaran inkuiri terhadap hasil belajar siswa pada materi pokok Suhu dan Kalor di Kelas X Semester II SMA Negeri 4 Medan T. P 2014/2015.

\section{METODE PENELITIAN}

Penelitian ini dilaksanakan di SMA Negeri 4 Medan Jalan Gelas No 12 Ayahanda Medan dan waktu penelitian dilaksanakan pada bulan Januari - Juli Tahun Pembelajaran 2014/2015.

Populasi dalam penelitian ini adalah seluruh siswa kelas X MIA SMA Negeri 4 Medan T.P 2014/2015 yang terdiri dari 11 kelas. Sampel dalam penelitian ini diambil dua kelas dengan cara cluster random sampling, yaitu kelas X-7 yang diajarkan dengan menggunakan model pembelajaran inkuiri dan kelas $\mathrm{x}-3$ yang diajarkan dengan pembelajaran konvensional.

Jenis penelitian ini termasuk jenis penelitian quasi eksperimen yang bertujuan untuk memperoleh informasi dengan memberikan suatu perlakuan terhadap kelompok siswa dengan menggunakan model pembelajaran.

Pada penelitian ini desain yang digunakan adalah two group pre-tes and post-tes design. Dalam desain ini diberikan perlakuan sebanyak dua kali pengukuran yaitu sebelum dan sesudah perlakuan. Test sebelum perlakuan disebut pre-test dan tes setelah perlakuan disebut post-test. Rancangan eksperimen ditunjukkan dalam Tabel 1.

Tabel 1. Two group pretes-postes design

\begin{tabular}{|l|c|c|c|}
\hline Sampel & Pretes & Perlakuan & Postes \\
\hline $\begin{array}{l}\text { Kelas } \\
\text { eksperimen }\end{array}$ & $\mathrm{T}_{1}$ & $\mathrm{X}_{1}$ & $\mathrm{~T}_{2}$ \\
\hline Kelas kontrol & $\mathrm{T}_{1}$ & $\mathrm{X}_{2}$ & $\mathrm{~T}_{2}$ \\
\hline
\end{tabular}

Keterangan :

$\mathrm{T}_{1} \quad$ : Pretes yang diberikan kepada kelas eksperimen dan kelas kontrol sebelum diberikan perlakuan. Tes yang diberikan berupa tes Pilihan Berganda pada materi pokok Suhu dan Kalor

$\mathrm{T}_{2} \quad$ : Postes yang diberikan setelah perlakuan kepada kelas eksperimen dan kelas kontrol.

$\mathrm{X}_{1} \quad$ : Model Pembelajaran Inkuiri

$\mathrm{X}_{2}$ : Model Pembelajaran Konvensional

Adapun instrumen/alat pengumpul data yang digunakan dalam penelitian ini adalah : untuk tes hasil belajar berupa tes pilihan berganda yang berjumlah 20 soal, untuk observasi aktivitas belajar siswa, peneliti dibantu oleh observer untuk mengamati aktivitas belajar siswa selama 
proses pembelajaran, yang sudah terdaftar secara sistematis di lembar observasi.

Uji validitas yang digunakan dalam penelitian ini yaitu validitas isi. Pengujian hipotesis ada dua cara yaitu: uji t untuk mengetahui kemampuan awal siswa pada kedua kelas yaitu pada kelas eksperimen dan kelas kontrol. Hipotesisnya adalah :

$\mathrm{H}_{\mathrm{o}}$ :

$\mathrm{H}_{\mathrm{a}}$ :

Keterangan :

: Kemampuan awal siswa pada kelas eksperimen sama dengan kemampuan awal siswa pada kelas kontrol.

: Kemampuan awal siswa pada kelas eksperimen tidak sama dengan kemampuan awal siswa pada kelas kontrol.

\section{HASIL DAN PEMBAHASAN \\ Hasil Penelitian}

Di bawah ini adalah tabel-tabel dari nilai rata-rata, uji normalitas, uji homogenitas dari pretes dan postes kedua kelas secara ringkas.

Tabel 2. Nilai Rata-rata Pretes dan Postes Kedua Kelas

\begin{tabular}{|c|c|c|}
\hline \multirow{2}{*}{ Kelas } & \multicolumn{2}{|c|}{ Rata-Rata } \\
\cline { 2 - 3 } & Pretes & Postes \\
\hline Eksperimen & 29,08 & 55,26 \\
\hline Kontrol & 27,86 & 48.14 \\
\hline
\end{tabular}

Tabel 2 menunjukkan bahwa nilai rata-rata pretes pada kedua kelas hampir sama, sedangkan setelah diberikan perlakuan diperoleh bahwa nilai rata-rata postes kelas eksperimen lebih tinggi dibandingkan di kelas kontrol.

Tabel 3. Perhitungan Uji Normalitas Pretes dan Postes

terima $\mathrm{H}_{\mathrm{O}}$ jika dimana didapat dari daftar distribusi t dengan $d k=\mathrm{n}_{1}+\mathrm{n}_{2}-2$ dan Untuk harga t lainnya $\mathrm{H}_{\mathrm{o}}$ ditolak.

Hipotesis satu pihak menggunakan uji $\mathrm{t}$ digunakan untuk melihat pengaruh dari model pembelajaran inkuiri terhadap hasil belajar siswa.

Hipotesisnya adalah :

$H_{0}$ :

$H_{a}$ :

Keterangan :

$H_{0}$ : :Hasil belajar siswa pada kelas eksperimen dan kelas kontrol sama, berarti tidak ada pengaruh model pembelajaran inkuiri

$H_{a}$ : : Hasil belajar siswa pada kelas eksperimen lebih besar daripada kelas kontrol, berarti pengaruh model pembelajaran inkuiri ada

Kriteria pengujian adalah :

terima $\mathrm{H}_{0}$, jika dimana didapat dari daftar distribusi $\mathrm{t}$ dengan peluang (1-) dan $\mathrm{dk}=$ $\mathrm{n}_{1}+\mathrm{n}_{2}-2$ dan . Untuk harga $\mathrm{t}$ yang lain $\mathrm{H}_{\mathrm{O}}$ ditolak.

\begin{tabular}{|l|l|c|c|c|}
\hline Data & Kelas & $\mathbf{L}_{\text {hitung }}$ & $\mathbf{L}_{\text {tabel }}$ & $\begin{array}{c}\text { Kesimpu } \\
\text { lan }\end{array}$ \\
\hline quetes & $\begin{array}{l}\text { Eksperime } \\
\mathrm{n}\end{array}$ & 0,1396 & 0,1437 & Normal \\
\cline { 2 - 5 } Poste & Kontrol & 0,1266 & 0,1498 & Normal \\
\cline { 2 - 5 } & $\begin{array}{l}\text { Eksperime } \\
\mathrm{n}\end{array}$ & 0,0841 & 0,1437 & Normal \\
\cline { 2 - 5 } & Kontrol & 0,1211 & 0,1498 & Normal \\
\hline
\end{tabular}

Tabel 3 menunjukan bahwa data pretes dan data postes berdistribusi normal. Hal ini terlihat dari harga $\mathrm{L}_{\text {hitung }}$ tidak melebihi $\mathrm{L}_{\text {tabel }}\left(\mathrm{L}_{\text {hitung }}<\mathrm{L}_{\text {tabel }}\right)$ yang mengindikasikan bahwa data berdistribusi normal.

Tabel 4. Perhitungan Uji Homogenitas Pretes dan Postes

\begin{tabular}{|c|l|c|c|c|}
\hline Data & \multicolumn{1}{|c|}{ Kelas } & $\mathbf{F}_{\text {hitung }}$ & $\mathbf{F}_{\text {tabel }}$ & Kesimpulan \\
\hline Pretes & Eksperimen & 1,063 \\
& Kontrol & 8 & 1,759 & Homogen \\
\hline \multirow{2}{*}{ Postes } & Eksperimen & \multirow{2}{*}{1,293} & 1,759 & Homogen \\
\cline { 2 - 5 } & Kontrol & \multicolumn{2}{|c}{} \\
\hline
\end{tabular}

Berdasarkan Tabel 4 diketahui bahwa sampel yang berupa kelas eksperimen dan kelas kontrol berasal dari populasi yang homogen. Hal ini terlihat dari harga $F_{\text {hitung }}$ 
tidak melebihi $\mathrm{F}_{\text {tabel }}\left(\mathrm{F}_{\text {hitung }}<\mathrm{F}_{\text {tabel }}\right)$ yang mengindikasikan bahwa sampel berasal dari populasi yang homogen.

Tabel 5. Perhitungan Uji Hipotesis

\begin{tabular}{|c|c|c|c|}
\hline $\begin{array}{c}\text { Uji } \\
\text { Hipotesis }\end{array}$ & $\mathbf{t}_{\text {hitung }}$ & $t_{\text {tabel }}$ & Kesimpulan \\
\hline $\begin{array}{l}\text { Uji t dua } \\
\text { pihak }\end{array}$ & 0,528 & $\begin{array}{c}1,996 \\
3\end{array}$ & $\begin{array}{c}\mathrm{H}_{0} \text { diterima } \\
\text { (Kemampuan awal } \\
\text { kedua kelas sama) }\end{array}$ \\
\hline $\begin{array}{c}\text { Uji t satu } \\
\text { pihak }\end{array}$ & 3,06 & $\begin{array}{c}1,668 \\
2\end{array}$ & $\begin{array}{c}\mathrm{H}_{\mathrm{a}} \text { diterima (Ada } \\
\text { pengaruh model } \\
\text { pembelajaran inquiry } \\
\text { training) } \\
\end{array}$ \\
\hline
\end{tabular}

Berdasarkan hasil uji $t$ dengan menggunakan data pretes diperoleh harga $\mathrm{t}_{\text {hitung }}<\mathrm{t}_{\text {tabel }}$ yaitu $0,528<1,9963$, berarti $\mathrm{H}_{\mathrm{o}}$ diterima yaitu kemampuan awal siswa pada kelas eksperimen sama dengan kemampuan awal siswa pada kelas kontrol. Untuk uji t yang menggunakan data postes diperoleh bahwa $t_{\text {hitung }}>t_{\text {tabel }}$ yaitu 3,06 $>1,6682$ pada taraf signifikansi 0,05 berada pada $\mathrm{dk} 60$ dan dk 120. Dapat diambil kesimpulan bahwa hipotesis $\mathrm{H}_{\mathrm{a}}$ diterima yaitu ada pengaruh yang signifikan model pembelajaran inkuiri terhadap hasil belajar siswa pada materi pokok Suhu dan Kalor di kelas X semester II di SMA Negeri 4 Medan T.P 2014/2015.

Tabel 6. Perhitungan Observasi Aktivitas Siswa

\begin{tabular}{|l|c|c|c|c|}
\hline Kelas & $\begin{array}{c}\text { Visual } \\
(\boldsymbol{\%})\end{array}$ & $\begin{array}{c}\text { Oral } \\
(\mathbf{\%})\end{array}$ & $\begin{array}{c}\text { Listening } \\
(\mathbf{\%})\end{array}$ & $\begin{array}{c}\text { Writin } \\
\mathbf{g} \\
(\boldsymbol{\%})\end{array}$ \\
\hline $\begin{array}{l}\text { Eksperi } \\
\text { men }\end{array}$ & 88,38 & 89,48 & 87,94 & 88,38 \\
\hline Kontrol & 33,33 & 68,10 & 33,33 & 78,57 \\
\hline
\end{tabular}

Berdasarkan hasil observasi aktivitas siswa diperoleh bahwa rata-rata persentase perhitungan aktivitas belajar siswa kelas eksperimen tergolong sangat baik untuk setiap emotional tergolong cukup baik, serta aspek writing tergolong baik.

\section{Pembahasan}

Penelitian

ini bertujuan untuk mengetahui hasil belajar siswa dan bagaimana aktivitas belajar siswa pada materi pokok Suhu dan Kalor dengan menggunakan

model pembelajaran inkuiri dan konvensional di kelas X semester II SMA Negeri 4 Medan T.P 2014/2015 serta untuk mengetahui apakah ada perbedaan yang signifikan model pembelajaran

inkuiri tersebut. Menurut Sardiman (2009) bahwa dalam kegiatan belajar, peserta didik harus aktif berbuat, dengan kata lain dalam belajar sangat dibutuhkan aktivitas. aktivitas, proses belajar tidak mungkin

berlangsung dengan baik, aspek aktivitas belajar yang diteliti yaitu, visual, oral, listening, writing, motor, mental, dan emotional.

Sebelum diberi perlakuan pada kedua sampel, terlebih dahulu diberikan pretes untuk melihat kemampuan awal siswa, dan nilai rata-rata pretes siswa kelas eksperimen sebesar 29,08 sedangkan untuk kelas kontrol sebesar 27,86. Setelah dilakukan uji kemampuan awal (uji hipotesis dua pihak), diperoleh bahwa kemampuan awal siswa pada kelas eksperimen dan kelas kontrol sama. Kemudian peneliti melakukan perlakuan yang berbeda pada kedua sampel selama empat kali pertemuan. Setelah diberi perlakuan, kemudian kedua sampel diberikan postes untuk mengetahui hasil belajar siswa. Hasil penelitian menunjukkan bahwa nilai rata-rata hasil belajar siswa kelas eksperimen sebesar 55,26 dan kelas kontrol sebesar 48,14. Hal tersebut menunjukkan

bahwa rata-rata hasil belajar siswa setelah diberiperlakuan pada kelas eksperimen lebih 
tinggi daripada

kelas kontrol, atau

dapat dikatakan ada

perbedaan yang

signifikan hasil

postes kedua kelas,

sehingga

menunjukkan

adanya pengaruh

yang signifikan

penggunaan model

pembelajaran

Inkuiri untuk

meningkatkan hasil

belajar siswa pada

materi pokok Suhu

dan Kalor di kelas

X SMA N 4 Medan

T.P. 2014/2015, dan

berdasarkan hasil

perhitungan,

peningkatannya

sebesar $\quad 14,79 \%$.

Untuk membuktikan

apakah benar-benar

ada pengaruh yang

signifikan, maka

dilakukan uji

hipotesis satu pihak

dengan taraf

signifikan 0,05 dan

$d k=71$, dan

diperoleh bahwa

ada pengaruh yang

signifikan

pengggunaan model

pembelajaran

Inkuiri tersebut.

Aktivitas belajar

siswa kelas

eksperimen dan

kontrol juga

berbeda, hal ini

dapat dilihat dari

hasil observasi

aktivitas belajar

siswa yang

menunjukkan

bahwa rata-rata

persentase perhitungan

aktivitas belajar

siswa kelas

eksperimen dengan

menggunakan

model pembelajaran

inkuiri tergolong

sangat baik untuk

setiap aspek

penilaian, dan rata-

rata persentase

perhitungan

aktivitas belajar

siswa kelas kontrol

dengan

menggunakan

model pembelajaran

konvensional untuk

aspek

visual,

listening,

motor,

dan mental

tergolong tidak

baik, dan untuk

aspek oral dan

emotional tergolong

cukup baik, serta

aspek writing

tergolong baik.

Pada

penelitian ini, hasil

penggunaan model

pembelajaran

inkuiri lebih baik

daripada

penggunaan model

pembelajaran

konvensional,

karena memberikan

peluang kepada

siswa untuk aktif

dalam

pembelajaran, hal

ini dapat dilihat

melalui langkah-

langkah dalam

model pembelajaran

Inkuiri khususnya

pada langkah ke

empat

(mengumpulkan data) dan didukung

dengan adanya

praktikum di kelas

eksperimen yang

merupakan bagian

dari model

pembelajaran

inkuiri.

Pada

langkah ke empat

model pembelajaran

Inkuiri, dimana

siswa

mengumpulkan data

untuk menjawab

pertanyaan yang

diberikan

sebelumnya. Untuk

proses pengumpulan

data, siswa

melakukan

penyelidikan secara

berkelompok

dengan

bereksperimen

langsung. Melalui

eksperimen, siswa

lebih aktif dalam

proses

pembelajaran, hal

ini didukung dengan

indikator observasi

akivitas belajar

siswa di kelas

eksperimen lebih

banyak tercapai

daripada di kelas

kontrol. Ada 7

indikator observasi

akivitas belajar

siswa yang diamati

dalam penelitian ini,

4 diantaranya hanya

dapat dilakukan

oleh siswa kelas

eksperimen, yaitu:

visual

(memperhatikan dan

aktif

dalam

percobaan),

listening (mendengar arahan

guru sehingga

berhasil dalam

melakukan

percobaan), motor

(melakukan

percobaan dengan

baik dan

memperoleh data

untuk didiskusikan

dalam kelompok)

dan mental

(mengolah data

hasil percobaan dan

menghasilkan

jawaban yang

benar). Pada saat

melaksanakan

eksperimen

dibutuhkan

ketekunan

dan

kemampuan

menggunakan

potensi berpikir

siswa yang sudah

dimiliki

sebelumnya. Hal-

hal tersebutlah yang

membuat

penggunaan model

pembelajaran

inkuiri lebih baik

daripada

penggunaan model

pembelajaran

konvensional, selain

itu pada saat

praktikum di kelas

eksperimen, peneliti

mengajukan

pertanyaan-

pertanyaan yang

dapat mendorong

peserta didik untuk

berpikir mencari

informasi yang

dibutuhkan sesuai

dengan pertanyaan.

Sama halnya dalam

(Sani, 2014) bahwa 


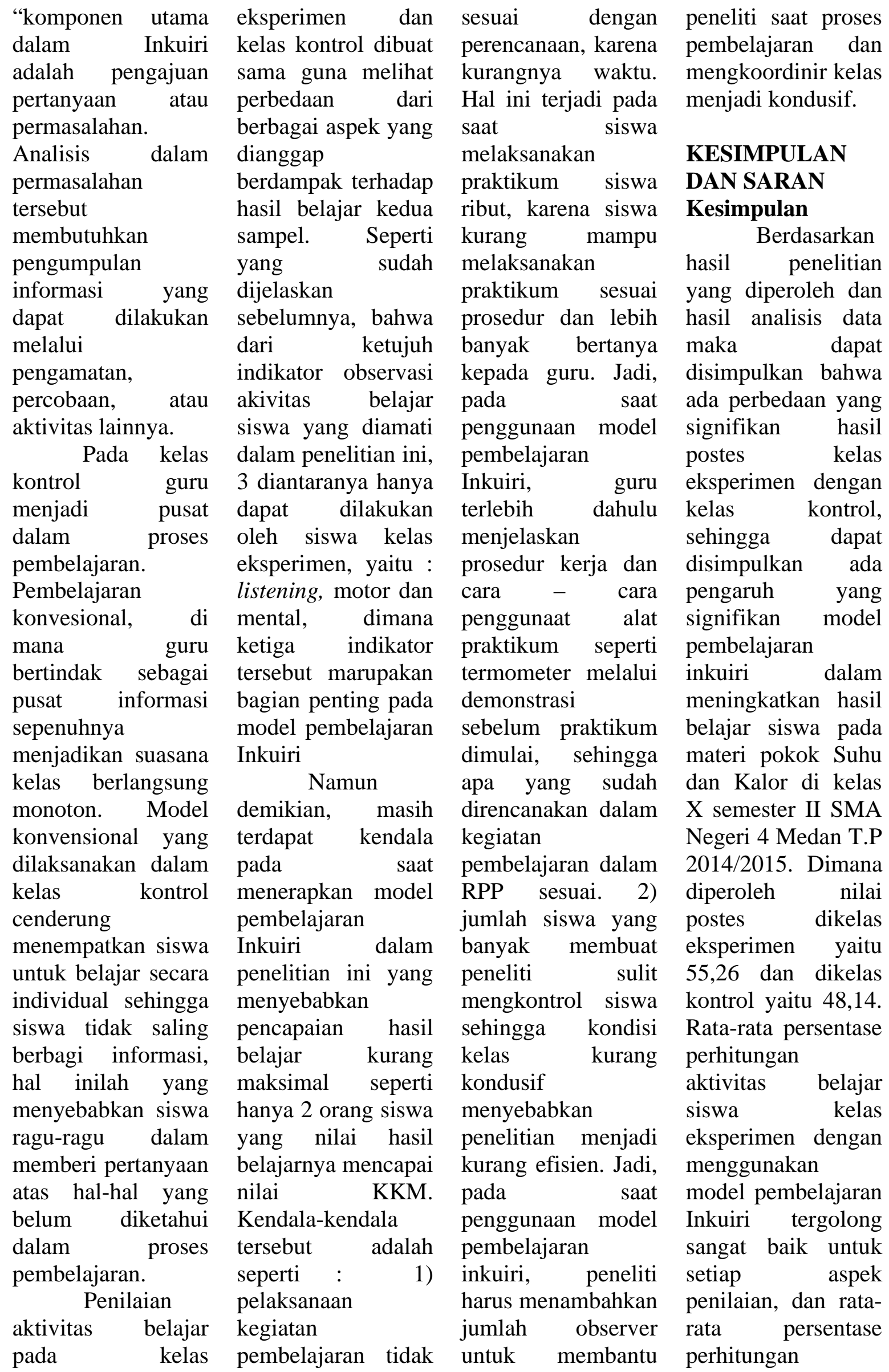




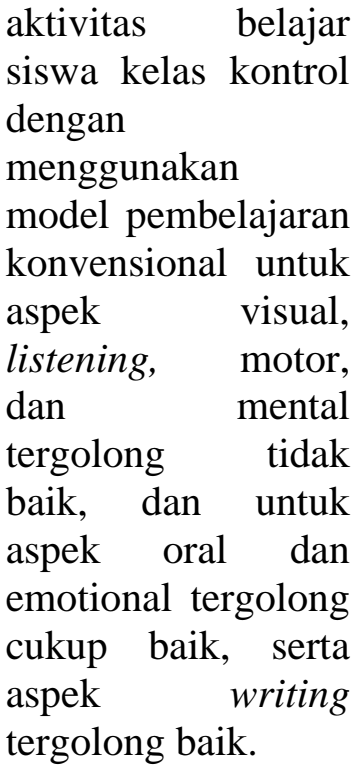

Saran

Berdasarkan

hasil penelitian dan

kesimpulan

penelitian, maka

beberapa hal yang

dapat penulis

sarankan adalah :

bagi siswa,

diharapkan agar

lebih serius lagi

dalam

pembelajaran,

seperti

mendengarkan dan

memperhatikan

penjelasan guru,

tidak menggunakan

alat komunikasi

selama

pembelajaran

berlangsung, agar

siswa dapat

mengerti apa yang

sedang dipelajari

nilai hasil belajar

meningkat. Bagi

guru, dalam proses

pembelajaran harus

peka dan tegas

kepada setiap siswa,

pada

saat

pelaksanaan

praktikum, guru harus aktif bertanya

kepada siswa

mengenai praktikum tersebut dan mampu memberi jawaban

yang benar jika ada

siswa yang kurang

paham pada saat

praktikum. Bagi

peneliti selanjutnya

diharapkan agar

selalu

memperhitungkan

alokasi waktu yang sudah dibuat di RPP

dan diawal

pembelajaran

terlebih dahulu

memberi arahan

tentang tujuan

pembelajaran yang

akan dicapai, sistem

penilaian, dan

pelaksanaan

praktikum terutama

penggunaan alat-

alat praktikum,

sehingga proses

pembelajaran dapat

berjalan sesuai

rencana. Kemudian, sebaiknya observer

pada penelitian

minimal ada dua,

jika jumlah siswa

banyak, karena

selain mengamati

aktivitas belajar tiap

siswa di dalam

kelas, observer juga

bertugas membantu

peneliti jika ada

siswa yang kurang

paham dalam proses

pembelajaran.

\section{DAFTAR \\ PUSTAKA}

Giancoli, (2001),

Fisika Edisi

Kelima Jilid

1, Erlangga,

Jakarta.

Hosnan, M., (2014),

Pendekatan

Saintifik dan

Kontektual

dalam

Pembelajaran

Abad 21,

Ghalia

Indonesia,

Jakarta.

Lie, A., (2010),

Cooperative

Learning:

Mempraktikka

$n$ Cooperative

Learning di

Ruang-ruang

Kelas,

PT.Gramedia

Widiasarana

Indonesia,

Jakarta.

Sani, R. A., (2014),

Pembelajaran

Saintifik

untuk

Implementasi

Kurikulum

2013, Bumi

Aksara,

Jakarta.

Sardiman, (2009),

Interaksi

dan

Motivasi

Belajar

Mengajar,

PT Raja

Grafindo

Persada,

Jakarta.

Sari, S. R., (2013),

Pengaruh

Model

Pembelajaran
Inquiry

Terhadap

Hasil Belajar

Siswa Pada

Materi Pokok

Listrik

Dinamis $\quad D i$

Kelas $\quad X$

Semester II

SMA Negeri

16 Medan T.P

2012/2013.,

Skripsi,

FMIPA,

Unimed,

Medan.

Tarigan, Y. E.,

(2012)

Perbedaan

Hasil Belajar

Siswa

Menggunakan

Model

Pembelajaran

Inkuiri

dengan

Konvensional

Pada Materi

Pokok Zat

Dan

Wujudnya di

Kelas VII

SMP

BRIGJEND

KATAMSO

Medan

Sunggal

Semester

Ganjil Tahun

Ajaran

2011/2012.,

Skripsi,

FMIPA,

Unimed,

Medan.

Tiarmaida, (2014),

Pengaruh

Model

Pembelajaran

Inkuiri 
Terhadap
Hasil Belajar

Siswa Pada

Materi Pokok

Listrik

Dinamis $\quad d i$

Kelas $\quad X$

Semester II

SMA Negeri 8

Medan T.P

2013/2014.,

Skripsi,

FMIPA,

Unimed,

Medan.
Trianto, (2011),

Mendesain

Model

Pembelajara

$n$ Inovatif-

Progresif,

Kencana

Prenada

Media

Group,

Jakarta. 
